\title{
LAS SENTENCIAS DEL TRIBUNAL EUROPEO DE DERECHOS HUMANOS RELATIVAS A PARTIDOS POLÍTICOS Y A SINDICATOS
}

\author{
SENTENCES OF THE EUROPEAN COURT OF HUMAN RIGHTS \\ IN RELATION TO POLITICAL PARTIES AND TRADE UNIONS
}

\author{
Ma. Ascensión MARTín HUERTAS
}

RESUMEN: Existen dos notas que configuran el derecho de asociación dotándole de perfiles propios: su internacionalización, esto es, su carácter supranacional, y el profundo desarrollo de las garantías jurisdiccionales, de las garantías de los derechos humanos a través de la acción de los tribunales y de una técnica jurídica procesal sofisticada y progresivamente eficaz. Es precisamente en este marco donde despliega su protección el Tribunal Europeo de Derechos Humanos que, en la interpretación y aplicación del Convenio Europeo para la Protección de los Derechos Humanos y de las Libertades Fundamentales, ha alcanzado el máximo grado de perfección y desenvolvimiento técnico en el control jurisdiccional de los derechos fundamentales en general y del derecho de asociación en particular, permitiendo recurrir directamente a los particulares ante un tribunal internacional, cuya jurisdicción es de carácter obligatorio y automático.

Palabras clave: derecho de asociación; Convenio Europeo para la Protección de los Derechos Humanos y de las Libertades Fundamentales, Tribunal Europeo de Derechos Humanos, partidos políticos y sindicatos.
ABSTRACT: There are two features that shape freedom of assembly providing it with profiles of its own: its internationalisation, that is, its supranational character, and the great development of jurisdictional as well as human rights guarantees, through the judges' action and a sophisticated as well as a progressively more efficient procedural legal method. It is precisely within this framework where the European court of Human Rights displays its efficient protection which, both in the interpretation and application of the Convention for the Protection of Human Rights and Fundamental Freedoms, has reached the highest degree of perfection and technical development in the jurisdictional control of the fundamental freedoms on the whole and of the freedom of assembly in particular, allowing private individuals to directly appeal before an international court, whose jurisdictional character is both obligatory and automatic.

Descriptors: Right of Association, Convention for the Protection of Human Rights and Fundamental Freedoms, European Court of Human Rights, Political Parties and Trade Unions. 


\section{INTRODUCCIÓN}

\section{El artículo 11 del Convenio Europeo para la Protección de los Derechos Humanos y Libertades Fundamentales $(\mathrm{CEDH})^{1}$ establece:}

1. Toda persona tiene derecho a la libertad de reunión pacífica y a la libertad de asociación, incluido el derecho de fundar con otras sindicatos y de afiliarse a los mismos para la defensa de sus intereses.

2. El ejercicio de estos derechos no podrá ser objeto de otras restricciones que aquellas que, previstas por la ley, constituyan medidas necesarias, en una sociedad democrática, para la seguridad nacional, la seguridad pública, la defensa del orden y la prevención del delito, la protección de la salud o de la moral, o la protección de los derechos y libertades ajenos. El presente artículo no prohíbe que se impongan restricciones legítimas al ejercicio de estos derechos para los miembros de las fuerzas armadas, de la policía o de la administración del Estado. ${ }^{2}$

A pesar de que la formulación textual del artículo resalte la dimensión individual, "toda persona", de los derechos de reunión y de asociación,

1 Firmado en Roma el 4 de noviembre de 1950.

2 De entrada, llama la atención la regulación conjunta de dos derechos fundamentales, el de reunión y el de asociación que en las Constituciones de los países que forman parte del Consejo de Europa tienen un tratamiento diferenciado (artículos 21 y 22 en España). Juan María Bilbao Ubillos expone que aunque ambas libertades fundamentales poseen notas comunes ("son libertades de titularidad individual pero de ejercicio colectivo, y se configuran como instrumentos indispensables para la formación de una opinión pública libre en una sociedad democrática"), no obstante, presentan notables rasgos diferenciales: "en el caso de las reuniones no existe un vínculo estable entre las personas que se agrupan en un lugar y momento dados, ni una estructura organizativa permanente como soporte necesario". El mismo comentario en cuanto al tratamiento unificador en el artículo 11, suscita la regulación del derecho de sindicación que, a menudo, ha sido objeto de regulación especial respecto al estatuto general del derecho de asociación (en la Constitución Española en el artículo 28.1).

El autor últimamente citado pone, también, de relieve la significativa ubicación de este artículo detrás del que regula la libertad de expresión, ya que una de las virtualidades de los derechos de reunión y asociación es la de posibilitar dicha libertad. Véase Bilbao Ubillos, Juan María, "Las libertades de reunión y asociación: algunas vacilaciones en una trayectoria de firme protección", en García Roca, Javier y Santolaya Machetti, Pablo (coord.), La Europa de los derechos: el Convenio Europeo de Derechos Humanos, Madrid, Centro de Estudios Políticos y Constitucionales, 2009, pp. 629-690. 
es indudable que ambos responden a la fuerte tendencia a la sociabilidad impresa en todo ser humano. ${ }^{3}$

Por otro lado, el artículo 53 con carácter general precisa:

ninguna de las disposiciones del presente Convenio será interpretada en el sentido de limitar o perjudicar aquellos derechos humanos y libertades fundamentales que podrían ser reconocidos conforme a las leyes de cualquier alta parte contratante o en cualquier otro Convenio en el que ésta sea parte.

Ello significa que en ningún caso las limitaciones y restricciones establecidas en el CEDH pueden perjudicar los derechos reconocidos tanto en otros Convenios como en las normas internas de los Estados miembros, estableciendo así un estatus de mínimos en cuanto a la protección de los derechos fundamentales reconocidos en el Convenio Europeo de Derechos Humanos. ${ }^{4}$

Concretamente, el párrafo segundo del artículo 11 recoge un elenco de finalidades que pueden justificar la imposición de restricciones al ejercicio del derecho de asociación. ${ }^{5}$ La licitud de estas limitaciones queda supeditada a la concurrencia de un doble requisito: la necesidad de la medida restrictiva en una sociedad democrática y su posible proporcionalidad en relación con los objetivos y exigencias contempladas en dicho

3 Ridola, Paolo, “Commentario all'art. 11”, en Bartolo, S. Sergio et al. (coords.), Commentario alla Convenzione europea per la tutela dei diritti dell'uomo e delle libertà fondamentali, Padua, CEDAM, 2001, p. 352.

4 Así, por ejemplo, aunque en el Convenio Europeo de Derechos Humanos no se contiene ninguna referencia expresa a los convenios realizados en la órbita de la OIT aplicables a la libertad sindical, a diferencia de lo establecido en el artículo 22.3 del Pacto Internacional de Derechos Civiles y Políticos de 1966, el Tribunal Europeo de Derechos Humanos deberá tener en cuenta aquellos convenios al tratar de dicha libertad, en cuanto que, válidamente ratificados, hayan pasado a ser parte integrante del ordenamiento jurídico de los Estados.

5 A pesar de que la lista ha sido calificada por el TEDH de taxativa y, por ello, sujeta a una interpretación estricta, al realizar su tarea jurisdiccional se ha mostrado bastante tolerante apreciando las finalidades invocadas, en los casos concretos, por los Estados demandados. En este sentido, el artículo 18 establece con carácter general: "Las restricciones que, en los términos del presente Convenio, se impongan a los citados derechos y libertades no podrán ser aplicadas más que con la finalidad para la cual han sido previstas". 
artículo. ${ }^{6}$ Además, las posibles medidas limitativas que se impongan por las autoridades nacionales, han de estar previstas por la ley sin que en ningún caso sea viable la exclusión del núcleo central del derecho de asociación. $^{7}$

A la hora de materializar los tests de necesariedad y proporcionalidad, los órganos del CEDH han concedido amplios márgenes de apreciación a los Estados adheridos al mismo, aunque no con un carácter ilimitado, sino supeditados a la fiscalización del Tribunal Europeo de Derechos Humanos (TEDH), ya que el control jurisprudencial ejercido es susceptible de diversas modulaciones en atención a las circunstancias concretas (las personas sobre las que recae la restricción, la gravedad intrínseca de la misma, etcétera). ${ }^{8}$ Con carácter general, el profesor Carrillo Salcedo ha puesto de manifiesto que dicha jurisprudencia se caracteriza por "la preocupación de equilibrio entre los intereses individuales y los intereses generales", citando en apoyo de su aserto la sentencia de 9 de diciembre de 1994, recaída en el caso López Ostra contra España. ${ }^{9}$

6 Para esta última cuestión se puede consultar García San José, Daniel Ignacio, Los derechos y libertades fundamentales en la sociedad europea del siglo XXI. Análisis de la interpretación y aplicación por el Tribunal Europeo de Derechos Humanos de la cláusula "necesario en una sociedad democrática", Sevilla, Secretariado de Publicaciones de la Universidad de Sevilla, 2001.

7 Como pone de manifiesto García San José, existen tres tipos de derechos: aquellos que gozan de protección relativa, cuasi absoluta y absoluta, en función de que su ejercicio pueda ser restringido en circunstancias normales en las condiciones previstas en sus segundos párrafos (artículos 8 a 11), sólo excepcionales, en virtud del artículo 15 que establece la posibilidad de derogar los derechos fundamentales en circunstancias excepcionales de guerra u otro peligro que amenace la vida de la nación (es la hipótesis de las garantías procedimentales del artículo 6 del $\mathrm{CEDH}$ ) o no admitan restricción ni derogación en ninguna circunstancia (artículos 2, 3, 4.1 y 7 del CEDH y los artículos 4 del Protocolo Adicional núm. 4, y 4 del Protocolo Adicional núm. 7). García San José, Daniel Ignacio, op. cit., nota anterior, pp.18 y ss.

8 Para un estudio detallado de esta materia, véase Bilbao Ubillos, Juan María, op. cit., nota 2, pp. 629-690.

9 El Tribunal estimó que se había violado el artículo 8 del CEDH ya que el Estado demandado "no ha sabido lograr un justo equilibrio entre el interés del bienestar de la ciudad de Lorca - disponer de una estación depuradora - y el disfrute efectivo por la demandante del derecho al respeto de su vida privada y familiar (apartado 58 de la sentencia), pues el respeto del derecho a su domicilio había sido conculcado a causa de la contaminación acústica y ambiental (humos y olores) provocada por dicha estación 
Teniendo en cuenta que el artículo 57 autoriza a los Estados parte a formular reservas con relación a concretas disposiciones contenidas en el Convenio (CEDH) siempre que se cumplan las previsiones establecidas en dicho precepto, ${ }^{10} \mathrm{y}$ en referencia concreta al Estado español, éste ha expresado, entre otras, reservas al artículo que recoge el derecho de asociación en la medida en que sea incompatible con los artículos 28 y 127 de la CE. ${ }^{11}$ En efecto, mientras que en el Convenio sólo se hace referencia a la posibilidad por parte de los Estados de imponer restricciones legítimas al derecho a fundar sindicatos y a afiliarse a los mismos, por parte de los miembros de las fuerzas armadas, de la policía o de la administración del Estado, ex artículo 11.2, nuestra ley fundamental contempla no sólo la posibilidad de limitar y establecer regímenes especiales respecto a estos colectivos, sino que habla también de exceptuar de tal libertad a las fuerzas o institutos armados o a los demás cuerpos sometidos a disciplina militar (artículo 28.1 CE). La Ley Orgánica 11/1985, de 2 de agosto, de libertad sindical ha materializado legislativamente dicha posibilidad al excluir en su artículo 1.3 el ejercicio de la libertad de sindicación tanto para las fuerzas armadas como para los institutos armados de carácter militar. ${ }^{12}$

En este panorama legislativo, la jurisprudencia del Tribunal Europeo ha venido a matizar y complementar los postulados legales recogidos en el Convenio Europeo, llevando a cabo una importantísima labor de con-

depuradora de aguas y residuos químicos”, Carrillo Salcedo, Juan Antonio, El Convenio Europeo de los Derechos Humanos, Madrid, Tecnos, 2003, p. 28.

10 Artículo 57. Reservas

1. "Todo Estado podrá formular, en el momento de la firma del presente Convenio o del depósito de su instrumento de ratificación, una reserva a propósito de una disposición particular del Convenio en la medida en que una ley en vigor en su territorio esté en desacuerdo con esta disposición. Este artículo no autoriza las reservas de carácter general".

2. "Toda reserva formulada de conformidad con el presente artículo irá acompañada de una breve exposición de la ley de que se trate".

11 BOE, Madrid, núm. 243, 10 de octubre de 1979.

12 Además, en cuanto a los sujetos comprendidos en tales restricciones y limitaciones, la Constitución Española se pronuncia también en términos de mayor amplitud al establecer, aparte de la exclusión mencionada, un régimen de asociacionismo profesional para jueces, magistrados y fiscales a los que también prohíbe la afiliación a partidos políticos y sindicatos mientras que se encuentren en activo; un régimen específico para los miembros del Cuerpo Nacional de Policía, considerado instituto armado, y ciertas peculiaridades para el ejercicio de este derecho por los funcionarios públicos. 
figuración del derecho de asociación, dominada por el respeto y fomento de la democracia, que no puede derivar en una dictadura de las mayorías, sino que debe permitir el adecuado respeto y un tratamiento justo para las minorías. Los pronunciamientos del Tribunal en esta materia, por un lado, han diseñado el concepto del derecho de asociación como libertad positiva y negativa referida a la dimensión individual, y por otro como unión voluntaria de personas para lograr determinadas finalidades, mediante el establecimiento de un ente que posee un vínculo estable. En esta labor de definición del derecho, el Tribunal ha especificado que el ejercicio de la libertad asociativa corresponde, no sólo a los individuos, sino que incluso se extiende a la propia asociación.

El estudio de la jurisprudencia más relevante del TEDH con relación al derecho de asociación arroja la conclusión de que se detecta una tendencia a juzgar las posibles violaciones de este derecho bajo la perspectiva del artículo 11 del CEDH, fundamentalmente en dos de las manifestaciones más paradigmáticas del derecho de asociación como son los sindicatos y los partidos políticos, ${ }^{13}$ ya que tratándose de otro tipo de asociaciones el Tribunal, a través de una opción de política jurisprudencial, prefiere analizarlas bajo otros derechos como el artículo 10 (libertad de expresión) o el artículo 9 (libertad religiosa) cuando se trate de asociaciones de marcado cariz religioso o ideológico.

\section{LAS SENTENCIAS DEL TRIBUNAL EUROPEO DE DERECHOS Humanos SOBRE SINDICATOS ${ }^{14}$}

El derecho a la libertad sindical está recogido expresamente en el artículo 11 del Convenio Europeo para la Protección de los Derechos Humanos y de la Libertades Fundamentales, a diferencia del derecho a

13 A pesar de tratarse en ambos casos de asociaciones, mientras que los partidos políticos expresan el pluralismo político, concurren a la formación y manifestación de la voluntad popular y son instrumento fundamental para la participación política (Jiménez Campos, Javier, "Voz partidos políticos", Enciclopedia Jurídica Básica, Madrid, Civitas, 1995, vol. III, p. 4791), en el caso de los sindicatos se trata de asociaciones permanentes de trabajadores por cuenta ajena para la defensa y protección de sus condiciones de vida y de trabajo (Rodríguez-Sañudo Gutiérrez, Fermín, "Voz sindicatos", Enciclopedia Jurídica Básica, Madrid, Civitas, vol. IV, 1995, p. 6225).

14 Para un estudio exhaustivo de las SSTEDH, véase Lasagabaster Herrarte, Iñaki, “Comentario al artículo 11 . Libertad de reunión y de asociación”, en Lasagabaster He- 
crear partidos políticos que se ha de deducir implícitamente. Lo que no se formula es un concepto de "sindicato", por lo que la jurisprudencia del Tribunal se ha acogido al comúnmente admitido en los Estados contratantes, que lo definen como una asociación estable de trabajadores o de empleados unidos para la defensa, la organización y la representación de intereses profesionales. ${ }^{15}$

Con gran claridad, Bilbao Ubillos expone que:

el Tribunal se ha visto obligado a deslindar, a golpe de sentencia, el contenido esencial de la actividad sindical que el Convenio protege de las facultades o prerrogativas accesorias que quedan fuera de esa esfera de protección. Y ha insistido una y otra vez en que el artículo 11 no garantiza a los sindicatos ni a sus miembros un determinado tratamiento por parte del Estado. ${ }^{16}$

Hay que tener en cuenta que la libertad sindical posee, como todo derecho de asociación, la doble vertiente individual, que protege el ámbito gremial de las personas, y colectiva, en la que la protección recae sobre las actividades del propio sindicato en defensa de los intereses de sus afiliados. El problema estriba en saber cuáles son las facultades que integran cada dimensión.

Empezando por uno de los aspectos más relevantes de la dimensión colectiva, como es el de la negociación colectiva, el TEDH ha tenido la oportunidad de pronunciarse sobre la posibilidad del ejercicio de esta práctica cuando el empleador resulta ser el poder público.

Así, en el asunto del Sindicato Nacional de la Policía belga contra Bélgica, ${ }^{17}$ donde se tuvo que apreciar si la decisión del legislador estatal de circunscribir la participación en consultas con el sector público a los sindicatos más representativos constituía una violación del artículo 11, el Tribunal comienza por aclarar que dicho artículo no da derecho al

rrarte, Iñaki (dir.), Convenio Europeo de Derechos Humanos. Comentario sistemático, Madrid, Civitas, 2009, pp. 567-617.

15 Para el estudio del derecho sindical en el ámbito del ordenamiento jurídico español se puede consultar Ojeda Avilés, Antonio, Derecho sindical, Madrid, Tecnos, 2003.

16 Bilbao Ubillos, Juan María, op. cit., nota 2, p. 659.

17 STEDH, Sindicato Nacional de la Policía belga contra Bélgica, de 27 de octubre de 1975, apartados 38-41. Para una visión más completa de la jurisprudencia del TEDH recaída sobre el artículo 11, se puede consultar la obra de Berger, Vincent, Jurisprudence de la Cour Européenne des Droits de l'Homme, París, Dalloz-Sirey, 2000, pp. 521-536. 
sindicato a la consulta y a la negociación con los poderes públicos. La sentencia expresa que los Estados gozan de libertad para elegir, entre los diversos medios compatibles con el artículo, aquellos que sean idóneos para la defensa de los intereses de los afiliados a un sindicato. De este modo, la política del Estado belga dirigida a restringir el número de organizaciones a negociar, teniendo en cuenta sólo las más representativas, no constituye per se violación de la libertad sindical, ya que los sindicatos cuentan con otras vías para ser escuchados en defensa de sus legítimos intereses.

La misma problemática que en el supuesto anterior se refleja en el asunto del Sindicato sueco de conductores de locomotoras contra Suecia. ${ }^{18}$ Se presenta, como cuestión principal, el posible derecho de un determinado sindicato a la negociación colectiva, actuando el Estado no como autoridad pública, sino como empleador. El Tribunal se pronunció en el sentido de no hacer acepción de tratamiento en cuanto a la aplicación del Convenio al Estado tanto si actúa investido de imperium como si lo hace en relaciones de derecho privado, y no reconoce que la negociación colectiva sea un derecho incluido en el elenco de facultades que se derivan de la libertad sindical, tal y como la configura el artículo 11 del Convenio.

Tampoco apreció el Tribunal que existía transgresión del artículo 11 por parte del gobierno sueco en el caso Schmidt y Dahlström. ${ }^{19}$ Además de reiterar la doctrina recogida en las dos sentencias anteriores, la alta instancia precisó que el derecho de concluir convenios colectivos, no constituía, en modo alguno, un elemento necesariamente inherente a un derecho garantizado por el $\mathrm{CEDH}^{20}$ y que el derecho de huelga, a pesar de constituir una forma de acción colectiva, garantizada a los sindicatos en el marco del Convenio, puede ser limitado por los Estados, en cuanto medio no exclusivo de defensa de los intereses colectivos, siempre que ello no comporte una total prohibición del ejercicio colectivo del derecho de huelga. ${ }^{21}$

18 STEDH, Sindicato sueco de conductores de locomotoras contra Suecia, de 6 de febrero de 1976 (apartados 37 y 39).

19 STEDH, Schmidt y Dahlström contra Suecia, de 6 de febrero de 1976 (apartados 34 y 36$)$.

20 Apartado 34 de la Sentencia.

21 Ridola, Paolo, op. cit., nota 3, p. 367. 
Más tarde, en el asunto Wilson, National Union of Journalists y otros contra Reino Unido, ${ }^{22}$ el TEDH insiste en el no reconocimiento del derecho a la negociación colectiva, que constituye uno solo de los diversos medios de transmitir las reivindicaciones sindicales al empleador, de ser escuchados, o de emprender las acciones que se estimen oportunas para defender los intereses de los trabajadores, siendo estos últimos elementos, en cambio, parte del contenido esencial. Sin embargo, se apreció violación del artículo 11 imputable al Estado británico, por permitir a los empleadores recurrir a incentivos económicos para lograr que los trabajadores renuncien a derechos sindicales importantes, incumpliendo así su obligación positiva de garantizar el disfrute efectivo de los derechos consignados en el citado precepto.

La línea jurisprudencial mantenida por el TEDH en materia de negociación colectiva tiene un punto de inflexión en el asunto Demir y Baykara contra Turquía. ${ }^{23}$ En dicha sentencia, el Tribunal comienza explicando que la evolución de la jurisprudencia sobre el contenido del derecho sindical está marcada por dos directrices: las medidas adoptadas por los respectivos Estados para hacer efectivo su ejercicio, ámbito en el cual se les deja un margen de apreciación siempre que queden, y ésta sería la segunda consideración, suficientemente asegurados los elementos que constituyen su contenido esencial. ${ }^{24}$ Después de enumerar los diversos vectores que constituyen dicho contenido, entre los que no se incluía la negociación colectiva, ${ }^{25}$ el Tribunal advierte que dicho elenco no constituye una lista cerrada, sino que la evolución del derecho sindical puede introducir variaciones. Así, en concreto en el aspecto de la negociación colectiva el Tribunal toma en cuenta los desarrollos del derecho del trabajo, tanto a nivel internacional como nacional y la práctica de los Estados miembros en la materia. De este modo, concluye afirmando que el derecho de llevar a cabo negociaciones colectivas con el empleador ha llegado a ser, en principio, uno de los elementos esenciales del derecho de sindicación

22 STEDH, Wilson, National Union of Journalists y otros contra Reino Unido, de 2 de julio de 2002 (apartados 41-48).

23 STEDH, Demir y Baykara contra Turquía, de 12 de noviembre de 2008.

24 Apartado 144 de la sentencia.

25 En efecto, los elementos enumerados son los siguientes: a) el derecho de formar un sindicato y de afiliarse a él; b) la prohibición de acuerdos de monopolio sindical, y c) el derecho para el sindicato de intentar persuadir al empleador que le escuche lo que tiene que decir en nombre de sus miembros. Apartado 145 de la sentencia. 
enunciado en el artículo 11. En todo caso, el Tribunal puntualiza que los Estados mantienen su libertad para aplicar, en caso de necesidad, un estatuto especial para los sindicatos más representativos. ${ }^{26}$

Otro gran bloque de problemas dilucidados por el Tribunal Europeo en relación con la libertad sindical hace referencia a la dimensión negativa de este derecho, dimensión que ha encontrado una excepción en la hipótesis de la llamada cláusula de "closed-shop system", que consiste en un acuerdo entre sindicatos y empresarios conforme al cual se exige que los trabajadores pertenecientes a determinadas categorías se afilien a una concreta organización sindical como condición para poder ser contratados en ciertas empresas o para conservar su puesto de trabajo, y que está admitida en algunos Estados que forman parte del Consejo de Europa, particularmente en el Reino Unido.

Las sentencias en torno a esta cuestión se inauguran con el caso Young, James and Webster contra Reino Unido, en el que los demandantes, trabajadores en los ferrocarriles británicos, fueron despedidos por no afiliarse a un sindicato cuya ideología no compartían. En la demanda plantean al Tribunal que dictamine si el artículo 11 garantiza, de forma implícita, la libertad negativa en el ámbito sindical. ${ }^{27}$ El Tribunal, aunque juzga innecesario pronunciarse al respecto, parte de la premisa de que también en materia sindical "una cierta libertad de elección en cuanto a ejercicio de una libertad es inherente a la noción misma de libertad", y que si se interpretase el artículo en el sentido de que permitiese "cualquier coerción en materia de pertenencia sindical, se atacaría la sustancia misma de la libertad en él garantizada". Por tanto, para valorar si en un caso concreto existe tal posibilidad de elección, se ha de verificar si no se ha vulnerado el principio según el cual "un individuo no goza de la libertad de asociación, si la libertad de acción o de elección que le queda resulta inexistente o reducida al punto tal de no ofrecerle ninguna utilidad".

En el asunto que nos ocupa los recurrentes habían visto conculcada su libertad de elección con la amenaza de despido, que implicaba la pérdida de sus medios de existencia, como así lo apreció el Tribunal. Éste no se mostró contundente a la hora de proclamar la incompatibilidad de los

26 Apartados 153 y 154 de la sentencia.

27 Recordemos que la Convención no reconoce, de manera expresa, el derecho de asociación negativa con carácter general, aunque el TEDH ha tenido ocasión de pronunciarse a favor de su reconocimiento. 
acuerdos de "closed-shop" con el artículo 11 del Convenio, pues explica que es necesario analizar caso por caso para valorar la incidencia de tales acuerdos sobre la libertad de elección de los demandantes. Sin embargo, estimó que en este supuesto se había transgredido el artículo en cuestión, resolución que fue adoptada por ocho votos contra tres.

A pesar de este tímido reconocimiento de la libertad sindical negati$\mathrm{va}^{28}$ en la sentencia examinada, se ha visto reforzada tal dimensión al ponerla en contacto con la protección de la libertad de conciencia y de opinión (artículos 9 y 10 del Convenio) que integran y refuerzan "los objetivos de la garantía de la libertad de asociación" al "afectar a la sustancia misma" de ésta "el ejercicio de presiones del género de las inferidas a los interesados, dirigidas a forzarles a adherirse a una asociación contrariamente a sus convicciones". ${ }^{29}$

Precisamente, la inexistencia de esta última coordenada fue uno de los motivos que el Tribunal adujo para emitir una sentencia desestimatoria en el caso Sibson contra Reino Unido. ${ }^{30}$ Por esta vía comparativa con el asunto anterior tampoco se reputaron parificables otras circunstancias, sobre todo porque en el caso Young James y Webster se daba la forma de presión más extrema que se puede ejercer sobre un trabajador: la amenaza de un despido real con la pérdida consiguiente de los medios de subsistencia. En el presente caso, se le concedía al trabajador la posibilidad de continuar desempeñando su trabajo, pero en otro lugar. Todas estas razones llevaron al Tribunal a pronunciarse en el sentido de que no existía la cláusula de "closed-shop" ni se había violado el artículo 11, por siete votos contra dos.

En el caso Sorensen y Rasmussen contra Dinamarca, ${ }^{31}$ ambos trabajadores fueron contratados con la condición de afiliarse al sindicato SID: el primero fue despedido sin preaviso al negarse a pagar las cuotas de afiliación a dicho sindicato, mientras que el segundo, dada su precaria

28 Mucho más expedito se mostró el juez Ganshof van der Meersch: “el aspecto negativo de la libertad de asociación es necesariamente complementario, correlativo e inseparable de su aspecto positivo. La salvaguardia de la libertad de asociación sería incompleta si se extendiera únicamente al aspecto positivo. No hay aquí más que un solo y mismo derecho".

29 STEDH, Young, James y Webster contra Reino Unido, de 13 de agosto de 1981, (apartados 52, 53, 55 y 57).

30 STEDH, Sibson contra Reino Unido, de 20 de abril de 1993.

31 STEDH, Sorensen y Rasmussen contra Dinamarca, de 11 de enero de 2006. 
situación económica, se vio obligado a continuar en este sindicato para conservar su puesto de trabajo. Presentado el asunto ante el Tribunal Europeo, éste declaró que imponer la obligación a asociarse a un sindicato no siempre va en contra del artículo 11 del Convenio, excepto que afecte a la sustancia misma del derecho de asociación. ${ }^{32}$ Además, dicho Tribunal subraya que entre los objetivos que se persiguen al garantizar la libertad de asociación se incluye el de garantía de la libertad de pensamiento y de expresión (artículos 9 y 10 del Convenio) que sólo pueden ser adecuadamente protegidas cuando se ampara tanto la libertad positiva como la libertad negativa del derecho de asociación. ${ }^{33}$ Sin embargo, el Tribunal matiza que una evaluación adecuada del nivel de protección de cada una de estas dimensiones que integran el derecho de asociación, sólo puede realizarse en el seno de la concreta práctica judicial. ${ }^{34}$ Reforzando su tesis, el Tribunal Europeo apunta también que el concepto de autonomía personal "debe ser considerado corolario esencial de la libertad de elección del individuo implícita en el artículo 11, así como elemento que confirma la importancia que reviste el aspecto negativo" 35 de este artículo. Por otro lado, ante la objeción del gobierno danés, según la cual este caso difiere del de Young al tratarse de una cláusula de "closed-shop" previa a la formalización del contrato, el Tribunal opone que el hecho de verse obligado a aceptar esta cláusula por imperiosas razones no implica la renuncia a la libertad de asociación negativa. ${ }^{36}$

En cuanto a la obligación por parte de los Estados miembros de garantizar positivamente los derechos reconocidos por el Convenio Europeo, y teniendo en cuenta que es preciso alcanzar un equilibrio entre los intereses colectivos y los individuales, las autoridades gubernativas pueden intervenir en el ámbito de las relaciones entre particulares. No obstante, disponen de un margen de apreciación muy reducido, cuando se trata de actuaciones encaminadas a reducir la libertad del individuo consagra-

32 Apartado 54. El Tribunal cita en su apoyo las sentencias Young y otros contra Reino Unido, de 13 de agosto de 1981, Gustafsson contra Suecia, de 25 de abril de 1996, y Siguröur A. Sigurjónsson contra Islandia, del 30 de junio de 1993.

33 Apartado 54. Hay que tener en cuenta que ambos demandantes alegaban que habían sido compelidos a formar parte de un sindicato en contra de sus convicciones ideológicas.
34 Apartado 56 de la sentencia.
35 Apartado 54 de la sentencia.
36 Apartado 56 de la sentencia 
da en el Convenio, singularmente en su artículo 11. ${ }^{37}$ En concreto, para comprobar si un Estado ha permanecido dentro de los márgenes permitidos a su libertad de apreciación, es necesario tomar en consideración tres coordenadas:

- los argumentos aducidos por las autoridades para justificar su intervención;

— el grado en que la libertad de asociación ha sido mermada por dicha actuación, y

— la utilidad del mantenimiento de los acuerdos del monopolio sindical. ${ }^{38}$

Además, el Tribunal recuerda que

aunque a veces sea necesario subordinar los intereses de los individuos a los de un grupo, la democracia no se reduce a la supremacía constante de la opinión de una mayoría, sino que exige un equilibrio que asegure a las minorías un tratamiento justo y que evite todo abuso de una posición dominante. ${ }^{39}$

Por todas estas razones, el Tribunal estimó por 12 doce votos a favor y cinco en contra, en el primero de los casos planteado en esta demanda, y por 15 votos contra dos en el segundo, que para ambos demandantes se había producido una violación del artículo 11, al verse afectada la sustancia misma de la libertad de elección sindical inherente al contenido esencial del derecho de asociación. En consecuencia, el gobierno danés fue condenado a pagar la correspondiente indemnización a los trabajadores.

Este asunto presenta el notable interés de que a través de él el Tribunal Europeo afirma, de modo categórico, que el aspecto negativo de la libertad de asociación está incluido en el artículo 11 del Convenio, si bien queda sujeta a modulación en atención a las circunstancias que presenten los casos concretos.

Finalmente, en el asunto Gustafsson contra Suecia se invierten los términos, ya que el sujeto pasivo de las presiones fue el dueño de un restaurante que, ante el boicot de que fue objeto por parte de un sindicato

37 Apartados 57 y 58 de la sentencia.

38 Apartado 58 de la sentencia.

39 Idem. 
al negarse a suscribir un convenio colectivo con sus trabajadores, se vio forzado a vender su negocio. Se ventilan aquí problemas nucleares en relación con la libertad sindical, pues se trata del derecho de refutar, por razones de orden político e ideológico —el empleador prefería conservar el vínculo personal de la relación que mantenía con sus asalariados-el sistema de la negociación colectiva con la consiguiente obligación de protección por parte del Estado. A juicio del Tribunal, el Convenio Europeo reconoce "la libertad de defender los intereses profesionales de los afiliados a un sindicato mediante las acciones colectivas de éste", siendo la negociación colectiva uno de los medios que el Estado puede arbitrar para asegurar el ejercicio de tal libertad. De ahí que la solución que se dé a cada caso concreto debe pasar por "buscar un justo equilibrio entre los intereses en juego", pero "la evaluación de la adecuación de la intervención del Estado con el fin de limitar las medidas adoptadas por el sindicato para acrecentar el alcance del sistema de la negociación colectiva" no puede prescindir de la necesidad de reconocer a los Estados contratantes "una gran amplitud en la elección de las medidas a emplear", por lo que el Tribunal estimó que el derecho a no suscribir convenios no goza de la esfera de protección del artículo 11 del Convenio. ${ }^{40}$

Mención especial merece un pronunciamiento del TEDH por la sustanciosa doctrina que desarrolla en torno a varias de las dimensiones esenciales del derecho de asociación. En efecto, en el caso Associated Society of Locomotive Engineers and Firemen (ASLEF) contra Reino Unido, de 27 de febrero de 2007, el Tribunal analiza la demanda del sindicato ASLEF, a quien se le impidió expulsar a uno de sus miembros debido a su pertenencia al British National Party, partido político cuyas opiniones son opuestas a las suyas. La instancia europea expone que, a su juicio, la finalidad esencial del artículo 11 del CEDH es la de proteger a la persona contra una injerencia arbitraria de las autoridades públicas en el ejercicio de los derechos protegidos. ${ }^{41}$ A raíz de este postulado empieza por afirmar la libertad de autorganización como una de las notas esenciales del derecho de asociación sindical, entendiendo por dicha libertad, entre otras cosas, la autonomía para establecer las condiciones de afiliación y de expulsión. ${ }^{42}$ "No se puede interpretar que el artículo

\footnotetext{
40 STEDH, Gustafsson contra Suecia, de 25 de abril de 1996 (apartados 45-46).

41 Apartado 37 de la sentencia.

42 Apartados 38 y 39.
} 
11 impone la obligación a las asociaciones u organizaciones de admitir a quienquiera que desee afiliarse a ellas". ${ }^{43}$ Al mismo tiempo, el Tribunal reconoce para cualquier empleado o trabajador la libertad positiva de asociarse a un sindicato y la libertad negativa de no hacerlo, "sin ser sancionado o sin sufrir trabas". ${ }^{44}$ Ambos aspectos del problema (libertad de autorregulación de la asociación y libertad de asociación del individuo) se encuentran matizados por el dato de la posible relevancia pública del ente asociativo del que se trate. En efecto, si se diera tal papel público, podría ser legítimo establecer la afiliación obligatoria o muy reglamentada. ${ }^{45}$ En este contexto, "el Estado deberá... proteger a la persona contra todo abuso de una posición dominante de los sindicatos", porque "la democracia no se reduce a la supremacía constante de la opinión de una mayoría". ${ }^{46}$ Dicho abuso podría producirse, en el caso de una expulsión, si ésta no se hiciera conforme a los estatutos, o bien si las normas estatutarias fuesen irrazonables, o incluso si las consecuencias de la exclusión constituyeran un daño considerable para el afiliado. ${ }^{47}$

Sobre estas premisas, el Tribunal intenta dilucidar hasta qué punto puede intervenir el Estado para proteger al miembro del sindicato contra las medidas de expulsión, y se pregunta si el Estado ha mantenido el equilibrio entre los derechos del individuo y los de la asociación sindical. El argumento central que usa dicha instancia para concluir, a favor del sindicato demandante, que sí hubo violación del artículo 11, estriba en observar que de la exclusión no se deriva, en este caso concreto, ninguna consecuencia grave para la persona, ya que no se está en un supuesto de relevancia pública ni de afiliación obligatoria. Tampoco estima el Tribunal que se produzca una merma del ejercicio de los derechos de expresión y de asociación del afiliado expulsado. ${ }^{48}$

El asunto Aguilera Jiménez y otros contra España, ${ }^{49}$ es sumamente interesante ya que en él se determina el alcance del derecho a la libertad de expresión en el marco de las actividades sindicales. El supuesto de

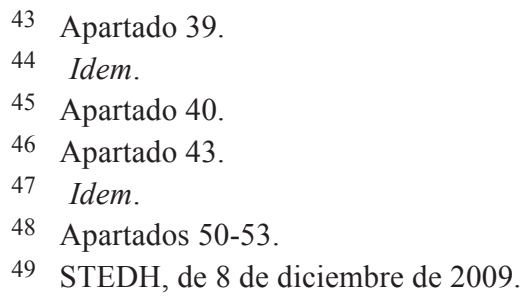


hecho que dio lugar a la STEDH es el siguiente: en el boletín mensual de un sindicato se publica una caricatura del director de recursos humanos y de dos compañeros en una actitud de claro componente sexual. Además, se hicieron eco de dos artículos en los que se denunciaba, de forma ofensiva, la asistencia a un juicio en calidad de testigos de estos dos empleados. Ante estos hechos, la empresa despidió a todos los profesionales involucrados en la edición del mencionado boletín. Agotadas las vías del recurso en España sin obtener una sentencia que les diera la razón, los trabajadores despedidos acudieron al Tribunal Europeo de Derechos Humanos, invocando la violación de los artículos 10 (libertad de expresión) y 11 del CEDH. Dicho órgano admitió a trámite el recurso y dictó una sentencia en la que, no obstante, de nuevo otorgó la razón a la empresa. El Tribunal estimó que el comportamiento de los trabajadores no estaba amparado por la libertad de expresión y por tanto era sancionable y el despido proporcionado a los hechos. ${ }^{50}$ En efecto, dicha libertad en ningún caso puede estimarse como absoluta, sino que queda sujeta a ciertos límites. ${ }^{51}$ En este caso los límites no fueron respetados, pues la caricatura y los artículos no eran otra cosa que ataques personales, ofensivos, ultrajantes, gratuitos e innecesarios para la legítima defensa de sus intereses. Distinta situación se hubiera ocasionado si los hechos se hubieran producido en el contexto de un intercambio oral, rápido y espontáneo; pero no era este el supuesto, ya que aquí se apreciaba una clara premeditación. ${ }^{52}$ En cuanto a la posible violación del artículo 11 del CEDH, tampoco se apreció la existencia de la misma con relación a dicho artículo ante la ausencia de indicios de que el despido de los demandantes fuera un acto de represalia por parte del empresario dada su pertenencia al sindicato en cuestión.

No obstante, uno de los magistrados del TEDH emitió un curioso voto particular. En él señala que el despido fue desproporcionado, al ser el sindicato de nueva creación, lo que justificaba, en su opinión, cierto tipo de conductas en aras de conseguir notoriedad y favorecer su implantación. ${ }^{53}$

50 Apartado 28 de la sentencia.

51 Apartado 32 de la sentencia.

52 Apartados 34 y 29 de la sentencia, respectivamente.

53 Opinión disidente de la jueza Power. 
Otra cuestión tratada por el Tribunal fue la problemática en torno al derecho de huelga que adquiere especial relevancia cuando se ejerce por funcionarios públicos.

En un asunto afín al anterior por tratarse también de medidas disciplinarias, tuvo que enjuiciar el órgano estrasburgués con ocasión del asunto Karaçay contra Turquía, de 27 de marzo de 2007. En este caso, un miembro de un sindicato se vio sancionado con un aviso por su participación en una jornada de huelga y de manifestación pacífica para defender el poder adquisitivo de los funcionarios. Aunque la sanción fuera muy leve, el TEDH consideró que no era necesaria en una sociedad democrática y podía disuadir a otros sindicalistas a la hora de participar en acciones de este tipo para defender los intereses de sus afiliados, por lo que concluyó la violación del artículo 11 del CEDH. ${ }^{54}$

En el asunto Enerji Yapei-Yol Sen contra Turquía, ${ }^{55}$ el Tribunal se enfrenta con las sanciones disciplinarias impuestas a unos funcionarios por haber participado en una jornada de huelga nacional para el reconocimiento del derecho a un convenio colectivo en el marco de los trabajos de armonización de la legislación turca con los convenios internacionales en materia de derecho sindical de los funcionarios estatales. El Tribunal especifica que el derecho de huelga no tiene carácter absoluto, al poder ser sometido a condiciones y restricciones. Sin embargo, si bien es cierto que dicha prohibición puede afectar a ciertas categorías de funcionarios, no es extensible a los funcionarios en general o a los trabajadores públicos de empresas comerciales o industriales del Estado. En el presente caso, se emitió una circular redactada en términos generales vetando de manera absoluta, a todos los funcionarios, el derecho de huelga en la jornada de acción nacional, cuando dicha jornada no estaba prohibida. El Tribunal estima que los funcionarios participantes en la mencionada jornada se han limitado a usar de su derecho de reunión y que, por tanto, las sanciones disciplinarias sufridas son medidas disuasorias contra los legítimos intereses de los funcionarios a participar legítimamente en las jornadas en defensa de sus intereses. Apunta el Tribunal en esta línea que el gobierno turco no ha demostrado la necesidad de usar esta medida en una sociedad democrática. ${ }^{56}$ Por todo ello, concluye que la adopción de

\footnotetext{
54 Apartados 37-39.

55 STEDH, de 21 de abril de 2009.

56 Apartado 32 de la sentencia.
} 
la circular no corresponde a una necesidad imperiosa, por lo que se ha producido una restricción desproporcionada de la libertad sindical. ${ }^{57}$

En este mismo contexto del derecho sindical de los funcionarios, se dan con cierta frecuencia casos de conflicto entre los funcionarios sindicados y el Estado con motivo de los traslados profesionales operados por éste. Así, en el asunto Ademyilmaz y otros contra Turquía ${ }^{58}$ en el que a causa de la dispersión geográfica llevada a cabo por el gobierno de los funcionarios pertenecientes a un mismo sindicato, se le demandó a dicho gobierno por atentar contra el derecho a la libertad de reunión y de asociación. Sin embargo, el Tribunal apreció por unanimidad que no existía ningún hecho ni argumento para concluir que las decisiones de traslado habían constituido una injerencia en estos derechos. Por el contrario, el Tribunal concluyó la vulneración del artículo 11 en el caso Metin Turan contra Turquía ${ }^{59}$ también con ocasión de un traslado de funcionario, porque aunque la libertad sindical "no asegura a los miembros de los sindicatos un trato determinado por parte del Estado ni, concretamente, el derecho a no ser trasladados", la decisión enjuiciada no se justificaba al no enmarcarse dentro de la gestión y del ejercicio de una buena administración de la función pública. La alta instancia reiteró dicho pronunciamiento en la sentencia Müslüm Çifçi contra Turquía. ${ }^{60}$

\section{LAS SENTENCIAS DEL TRIBUNAL EUROPEO DE DERECHOS HUMANOS RELATIVAS A PARTIDOS POLÍTICOS}

Si en un primer momento las decisiones del órgano garante del Convenio Europeo giran en torno al derecho de asociación en su manifestación de asociación sindical, en una segunda etapa se focalizan en los partidos políticos, que no han sido objeto de las decisiones del Tribunal hasta épocas recientes, sin dejar de enjuiciar materias sindicales. ${ }^{61}$

57 Apartado 33 de la sentencia.

58 STEDH, de 21 de marzo de 2006.

59 STEDH, de 14 de noviembre de 2006.

60 STEDH, de 2 de febrero de 2010 (apartado 35).

61 Carrillo Salcedo explica que las grandes transformaciones políticas acaecidas en Europa tras la desaparición del bloque ruso-soviético han erigido al Consejo de Europa en impulsor "en la difícil consolidación de democracias políticas pluralistas respetuosas del imperio del derecho en países que durante décadas habían sufrido regímenes políticos 
Prima facie, podemos preguntarnos si las formaciones políticas caen dentro del rango protector del artículo 11 del Convenio Europeo, que no se refiere expresamente a ellas. La cuestión fue zanjada ya por la Comisión en la primera demanda que se interpuso contra la disolución de un partido político y ha sido, posteriormente, reiterada por el Tribunal en diversas sentencias, a favor de la inclusión de los partidos en el ámbito de protección del artículo 11, ${ }^{62}$ ya que la democracia, uno de los pilares sobre los que descansa el reconocimiento de los derechos del hombre, ha de garantizar el pluralismo político como valor esencial en dicho sistema, ${ }^{63}$ junto con el libre debate de las ideas. De ahí que la libertad de asociación, aplicada a los partidos políticos, aparezca fuertemente conectada con otro derecho fundamental: la libertad de expresión contemplada en el artículo 10 del Convenio. ${ }^{64}$ Por su parte, el Tribunal Europeo ha puesto de manifiesto, a través de diferentes sentencias, esta fuerte vinculación del derecho de asociación, con la libertad de pensamiento, conciencia y religión, reguladas en el artículo 9 del CEDH, además de con la libertad de expresión, llegando a afirmar en forma tajante que "la protección de las opiniones personales ofrecida por los artículos 9 y 10 bajo la forma de libertad de pensamiento, de conciencia y religión así como de la libertad de expresión se encuentra, entre los objetivos de la libertad de asociación garantizada por el artículo 11" y que dichas libertades "serían de un alcance muy limitado si no fueran acompañadas de una garantía de poder compartir las ideas y creencias propias en comunidad con otros, particularmente, a través de asociaciones de individuos que tengan las mismas creencias, ideas o intereses". ${ }^{65}$

Aplicando esta doctrina a los partidos políticos, la libertad de expresión adquiere su máxima manifestación, ya que "forma parte de la esencia de la democracia permitir la propuesta y discusión de proyectos po-

totalitarios", por lo que ha pasado de ser un "club de democracias" a una "escuela de democracia”. Carrillo Salcedo, Juan Antonio, op. cit., nota 9, p. 14.

62 La demanda, rechazada por la Comisión del 20 de julio de 1957 (núm. 250/57), fue una del caso Partido Comunista de Alemania y otros contra Alemania.

63 Preámbulo del Convenio de Roma de 1950.

64 García San José, Daniel Ignacio, "La libertad de expresión en la jurisprudencia del Tribunal Europeo de Derechos Humanos: un análisis crítico", Revista del Poder Judicial, núm. 57, 2000, pp. 13-30.

65 Los párrafos citados corresponden al caso Chassagnou y otros contra Francia, de 29 de abril de 1999, apartados 57 y 100 
líticos distintos, incluso de aquellos que pongan en cuestión el modo de organización actual del Estado, con tal que no supongan un atentado a la propia democracia" pudiendo llegarse, mediante aquella libertad, a expresar no sólo las informaciones o ideas favorables o inofensivas e indiferentes, sino también "las que contrarían, chocan o inquietan", lo que se justifica en atención a que "los límites de la crítica admisible son más amplios para el gobierno que para un simple particular". ${ }^{66}$

También se ha puesto en conexión la libertad de asociación, no sólo con la de pensamiento y expresión, sino también con la de reunión. Tal hipótesis sería la contemplada en el caso Çetinkaya contra Turquía, ${ }^{67}$ en el que se enjuicia una posible violación de la libertad de reunión de las autoridades turcas con respecto al dirigente de la asociación "Plataforma de la Democracia" (agrupación civil que engloba varios sindicatos, asociaciones y órdenes profesionales), por condenar una rueda de prensa que, a juicio de dichas autoridades, se convirtió en una reunión ilegal, basándose en la legislación turca sobre asociaciones, según la cual,

los dirigentes de asociaciones representando su asociación no pueden participar en reuniones y manifestaciones, hacer declaraciones que no correspondan a los objetivos y formas de actividad definidas en sus estatutos ni empujar a los miembros de la asociación a actuar en este sentido (artículo 37 de la Ley 2908, de 6 de octubre de 1983). ${ }^{68}$

El Tribunal Europeo, estimando que uno de los objetivos de la libertad de reunión pacífica (artículo 11 del Convenio) es la protección de las opiniones personales (artículo 10 del Convenio), ${ }^{69}$ no entró a conocer sobre

66 SSTEDH, Partido Socialista y otros contra Turquía, de 25 de mayo de 1998, apartados 47, 41, 45; Partido Comunista Unificado de Turquía y otros contra Turquía, de 30 de enero de 1998, apartados 42, 43, 57; Partido de la Libertad y la Democracia contra Turquía, de 8 de diciembre de 1999, apartado 37. La última declaración se contiene en STEDH, Yaser, Baratas, Aksoy y Partido del Trabajo del Pueblo contra Turquía, de 9 de abril de 2002, apartado 59.

67 STEDH, de 27 de junio de 2006.

68 Apartado 18 de la sentencia.

69 En el caso Partido Nacionalista Vasco-Organización Regional de Iparralde contra Francia, de 7 de junio de 2007, el Tribunal insiste en que "la protección de las opiniones y de la libertad a expresarlas en el sentido del artículo 10 del Convenio constituye uno de los objetivos de la libertad de reunión y asociación que consagra el artículo 11" (apartado 33). 
la posible vulneración del artículo 10, centrándose exclusivamente en el examen de la trasgresión del artículo $11 .{ }^{70}$ Con base en ello decretó que, bajo ningún concepto (incluso cuando se tratare de una reunión ilegal) se puede menoscabar la libertad de participar en una reunión pacífica. ${ }^{71}$ En el presente caso, al haberse restringido el ejercicio de la libertad de reunión dentro de límites inciertos, pues estaba motivado por la apreciación de las autoridades nacionales, se conculcaron a la vez la libertad de asociación y el estado de democracia en Turquía. ${ }^{72}$

Por otro lado, deslindando el ámbito de actuación del órgano estrasburgués ratione materiae, éste ha tenido ocasión de señalar que "ninguna parte de la jurisdicción de los Estados miembros" se sustrae al "imperio del Convenio", de modo que "la organización institucional y política de los Estados miembros debe respetar los derechos y principios inscritos en el Convenio", importando "poco a este respecto que se enjuicien disposiciones constitucionales o legislativas". ${ }^{73}$

Los partidos políticos son los beneficiarios por excelencia de la libertad de asociación que, en este caso, se debe entender como derecho de fundar un partido y también como el derecho del partido de llevar a cabo libremente sus actividades políticas.

No obstante, en aplicación del segundo apartado del artículo 11, se legitima a los Estados para intervenir en el control del derecho de asociación gozando de un cierto "margen de apreciación" 74 sometido, en última instancia, a la fiscalización del Tribunal Europeo que, en relación con los partidos políticos, ha declarado que dicho margen es muy limitado:

70 Apartado 23 de la sentencia.

71 Apartado 27 de la sentencia.

72 Apartado 30 de la sentencia.

73 Caso Partido Comunista Unificado de Turquía contra Turquía, de 30 de enero de 1998 (apartados 24 y ss., especialmente 29 y 30).

74 De este modo, se intenta conjugar el universalismo de los derechos humanos con el relativismo de las tradiciones nacionales. Sobre la doctrina del margen de apreciación nacional se puede consultar García Roca, Javier, "Soberanía estatal versus integración europea mediante unos derechos fundamentales comunes: ¿cuál es el margen de apreciación nacional?", en García Roca, Javier y Fernández Sánchez, Pablo Antonio, Integración europea a través de derechos fundamentales: de un sistema binario a otro integrado, Madrid, Centro de Estudios Políticos y Constitucionales, 2009, pp. 15-53. 
las excepciones contempladas en el artículo 11 requieren, con respecto a los partidos políticos, una interpretación estricta, pudiendo únicamente razones convincentes e imperativas justificar restricciones a su libertad de asociación. Para juzgar en tal caso la existencia de una necesidad en el sentido del artículo 11.2 del CEDH, los Estados contratantes sólo disponen de un margen de apreciación reducido, que se duplica con un control europeo riguroso que afecta a la vez a la ley y a las decisiones que la aplican, incluidas las de un tribunal independiente... tal control se impone (a fortiori) cuando se trata de la disolución de todo un partido político y de la prohibición que afecta a sus responsables de ejercer en el futuro cualquier otra actividad similar. ${ }^{75}$

En la realización de su labor, el TEDH "debe convencerse de que las autoridades nacionales han aplicado las normas conforme a los principios consagrados por el artículo $11 \mathrm{y}$, además, basándose en una apreciación aceptable en los hechos pertinentes". ${ }^{76}$ En cuanto a los extremos a los que alcanza su supervisión al conocer de la disolución de un partido político son tres, ex artículo 11 de Convenio: la previsión por la ley nacional de la disolución del partido en cuestión; la finalidad legítima que se persigue con dicha disolución que, recordemos, ha de consistir en una medida necesaria en una sociedad democrática "para la seguridad nacional, la seguridad pública, la defensa del orden y la prevención del delito, la protección de la salud o de la moral o la protección de los derechos y libertades ajenos", finalidad que, con un criterio muy amplio, ha sido aceptada, sin problemas, por el Tribunal Europeo a la hora de justificar las autoridades públicas sus intervenciones; $y$, finalmente, el carácter necesario en una sociedad democrática de la disolución, constituyendo éste, el requisito que ha suscitado mayor complejidad para comprobar su concurrencia. En efecto, se trata ahora de constatar si la limitación adoptada (la disolución de un partido político) guarda proporción con los fines pretendidos, para cuya verificación el órgano de control europeo

75 En este sentido: SSTEDH, Partido Comunista Unificado de Turquía contra Turquía, de 30 de enero de 1998, apartado 46; Partido Socialista de Turquía contra Turquía, de 25 de mayo de 1998, apartado 50, y Partido de la Libertad y de la Democracia contra Turquía, de 8 de diciembre de 1999, apartado 44.

76 De ahí, entre otras, SSTEDH, Partido de la Prosperidad y otros contra Turquía, de 31 de julio 2001, apartado 52; Yaser, Baratas, Aksoy y Partido del Trabajo del Pueblo contra Turquía, STEDH, de 9 de abril de 2002, apartado 44. 
viene manejando una serie de datos (estatutos, programas ${ }^{77} \mathrm{y}$ actividades del partido, así como actividades de sus dirigentes — declaraciones públicas - etcétera), señaladamente, la vinculación contrastada del partido con la existencia de terrorismo en el país de que se trate y su impacto sobre los derechos incluidos en el Convenio.

Como puso de manifiesto el Tribunal, "la derrota del terrorismo es un interés público de primera importancia en una sociedad democrática". ${ }^{78}$ Pues bien, en esta ardua tarea se ha intentado buscar un delicado equilibrio entre "el legítimo derecho de una sociedad democrática a protegerse frente a las actividades de organizaciones terroristas" y "el obligado respeto por los Estados de los derechos y libertades enmarcados en el instrumento convencional". ${ }^{79}$ De ahí que cuando los partidos políticos Herri Batasuna y Batasuna demandaron al Estado español por estimar que su disolución fuese una violación de los artículos 10 y 11 del Convenio, el Tribunal admitió a trámite la demanda, en su sentencia Herri Batasuna y Batasuna contra España, de 11 de diciembre de 2007. ${ }^{80}$ En efecto, a la vista de todos los argumentos de las partes, dicha instancia europea consideró que "estas quejas plantean cuestiones serias tanto de hecho

77 La disolución definitiva de un partido político por el solo motivo de su programa y antes de que haya empezado sus actividades, constituye una violación del artículo 11, dada la desproporción de la decisión (STEDH, Partido Comunista Unificado de Turquía y otros contra Turquía, de 30 de enero de 1998, apartado 51).

78 Caso Purcell y otros contra Irlanda, de 16 de abril de 1991, apartado 35.

79 Sáiz Arnaiz, Alejandro, "La disolución de los partidos y el derecho de asociación: el test de convencionalidad (artículo 11 CEDH)", Actualidad Jurídica Aranzadi, núm. 533, 2002, p. 4.

80 Lógicamente, la ilegalización de dichas formaciones suscitó numerosos comentarios entre la dogmática española, se pueden consultar como más destacados: Martínez Sospedra, Manuel, "Sobre los efectos de la Ley Orgánica de Partidos Políticos: la ilegalización de Batasuna y el Parlamento Vasco", en Peña González, José (coord.), Homenaje a D. Íñigo Cavero Lataillade, Valencia, Tirant lo Blanch, 2005, pp. 429 y ss.; Morales Arroyo, José María, "Las consecuencias colaterales de la disolución de Batasuna", Revista Española de Derecho Constitucional, núm. 71, 2004, pp. 243 y ss.; Virgala Foruria, Eduardo, "El recorrido jurisprudencial de la suspensión y disolución de Batasuna: agosto de 2002 a mayo de 2007”, Revista Española de Derecho Constitucional, núm. 81, 2007, pp. 243 y ss., y "El intento de disolución del grupo parlamentario de Batasuna: ¿levantamiento del velo o vulneración de derechos?", Teoría y Realidad Constitucional, núm. 22, 2008, pp. 193 y ss. 
como de derecho que... necesitan ser examinadas a fondo". ${ }^{81}$ Así ocurriría puesto que el 30 de junio de 2009, el TEDH emitiría un dictamen definitivo sobre dicho caso, como veremos ahora.

En las numerosas sentencias en las que el Tribunal Europeo se ha pronunciado sobre el derecho de asociación en su vertiente política, destaca el hecho de que en todas ellas, el talante mostrado ha sido fuertemente garantista a favor de la subsistencia de las facciones políticas. No obstante, en las sentencias recaídas en el caso Refah Partisi (Partido de la Prosperidad) y otros contra Turquía ${ }^{82}$ y en el asunto Herri Batasuna y Batasuna contra España ${ }^{83}$ se apreció la válida intervención del Estado en la disolución de las dos formaciones. En ambos casos, el TEDH estudia la justificación de dicha injerencia en el derecho de asociación comprobando si se daban los tres criterios, ya mencionados, que hacen legítima la injerencia de cualquiera de los derechos contemplados en el Convenio. El cumplimiento de los dos primeros requisitos (la injerencia debe estar prevista en la ley y debe estar justificada para alcanzar uno o varios fines legítimos) no planteó mayores dudas, por lo que el peso de la argumenta-

\section{Apartado A de la valoración del Tribunal.}

82 De 31 de julio de 2001. Este asunto dio lugar a una controvertida sentencia fechada el 31 de julio de 2001, en la que, en una apretada votación (4 votos contra 3), se decidió la ilegalización del partido Refah, que fue posteriormente confirmada en la Gran Cámara por el Tribunal, en este caso, por unanimidad de los 17 miembros integrantes de la misma, el 13 de febrero de 2003. La sentencia ha suscitado diversos comentarios; véase, entre otros, Allué Buiza, Alfredo, "Pluralismo político en Turquía y el Tribunal Europeo de Derechos Humanos", Revista de Estudios Europeos, núm. 34, 2003, pp. 131-153. También Tajadura Tejada, Javier, "El Tribunal Europeo de Derechos Humanos", en Corcuera Atienza, Javier et al., La ilegalización de los partidos políticos en las democracias occidentales, Madrid, Dykinson, 2008, pp. 298-305.

83 De 30 de junio de 2009. En esa misma fecha se dictaron por el mismo Tribunal otras dos sentencias íntimamente relacionadas con la anterior: Etxeberria y otros contra España, que estableció la disolución de dichas agrupaciones electorales para las Juntas Generales y para Ayuntamientos del País Vasco, así como de Navarra y Herritarren Zerrende contra España, que hizo lo propio con sus agrupaciones para la elecciones europeas. En las tres sentencias, la Sala del Tribunal estuvo integrada por los mismos jueces (entre ellos el profesor vasco de Derecho constitucional Alejandro Sáiz Arnaiz), siendo muy significativo que las tres sentencias se dictaran por unanimidad. En el fondo, estas últimas agrupaciones eran una mera reproducción camuflada de Herri Batasuna, como se acreditó debidamente en el proceso. Véase Martín-Retortillo Baquer, Lorenzo, "La actividad política según la jurisprudencia del Tribunal Europeo de Derechos Humanos", Revista General de Derecho Administrativo, núm. 23, 2010. 
ción de estas sentencias recayó sobre el tercer punto (debe ser necesaria en una sociedad democrática). Tanto en el caso Refah Partisi como en el de Herri Batasuna, el TEDH recordó, antes que nada, la insoslayable vinculación de la libertad asociativa (artículo11 CEDH) con la libertad de expresión (artículo $9 \mathrm{CEDH}$ ), en beneficio de la democracia:84 "no hay democracia sin pluralismo". ${ }^{85}$ Por otra parte, apuntó al estrecho margen de actuación del que disponen los Estados para conculcar legítimamente el derecho de asociación, puesto que sólo "razones convincentes e imperativas", ${ }^{86}$ "pertinentes y suficientes" 87 pueden autorizar una intervención estatal en este ámbito. En definitiva, la línea directora que subyace a todo el desarrollo argumentativo realizado por el Tribunal en estos asuntos resulta ser siempre la conciliación de dos vertientes inseparables del derecho de asociación: su carácter de libertad individual y su dimensión y proyección social. Al igual que todo derecho fundamental, ${ }^{88}$ la libertad asociativa no se puede ejercer de un modo absoluto, porque no puede entenderse al margen de todo condicionamiento o vinculación. ${ }^{89}$ La socialidad del hombre implica que no existe derecho fundamental alguno ajeno a esa relación con los demás, lo cual se pone especialmente de manifiesto en el caso del derecho de asociación, de modo que no se puede llevar a cabo un ejercicio ilimitado del mismo. Así lo expresa el TEDH, aunque centrándose, como es lógico, debido al tenor de los asuntos tratados, en la vertiente política de la realidad social, es decir, en el fuerte componente democrático que ha de presentar dicha realidad. Llega

84 En relación con España y referida a la Ley Orgánica de Partidos Políticos, véase Tajadura Tejada, Javier, Partidos políticos y Constitución. Un estudio de la LO 6/2002, de 27 de junio, de partidos políticos y de la STC 48/2003, de 12 de marzo, Madrid, Civitas, 2004, pp. 136 y ss.

85 Refah Partisi, apartados 88 y 89; Herri Batasuna, apartados 74 y 76.

86 Refah Partisi, apartado 100.

87 Herri Batasuna, apartado 75.

88 Excepción hecha del derecho a la vida que sí ha de ser considerado absoluto no sólo porque no admite graduación en su disfrute (o se tiene por completo o se pierde del todo), sino también porque es condición de posibilidad, de existencia de todos los demás derechos fundamentales.

89 Ballesteros Llompart, Jesús, "Razones a favor de una postmodernidad alternativa", Doxa, núm. 6, 1989, p. 305. En palabras de Solozábal, la "condición social [del individuo] implica obligaciones con los intereses comunes y derechos de los demás". Solozábal Echavarría, Juan José, "Los límites de los derechos y el sistema normativo", Derecho Privado y Constitución, núm.17, 2003, p. 450. 
a afirmar que nadie puede utilizar la democracia para destruirla..$^{90}$ En las sentencias Refah Partisi y Herri Batasuna, la alta instancia detecta una amenaza grave e inminente a la democracia en la existencia de dichos partidos políticos, por lo que se pronuncia a favor de las disoluciones realizadas por los Estados turco y español, respectivamente. ${ }^{91}$

Este giro en la trayectoria sentada por el Tribunal Europeo, que le ha llevado a adoptar una medida tan "draconiana" 92 como es la disolución de un partido político, ha conducido a dicho organismo a señalar los límites, fuera de los que no se aplica la protección del Convenio a los partidos: se han de utilizar medios legales y democráticos (lo que excluye de raíz la violencia); el proyecto político, no sólo ha de respetar las reglas de la democracia, sino que además no debe pretender la supresión de la misma (en particular, queriendo hacer caso omiso de los derechos y libertades que ella garantiza). Frente a abusos de este género, un Estado miembro puede reaccionar, sin vulnerar el artículo 11 del Convenio. Cumpliría, de este modo, "la teoría de las obligaciones positivas, que implica, en particular, que el Estado ha de proteger los derechos garantizados contra atentados cometidos por terceros", ${ }^{93}$ y que ha sido innovada y reforzada por el Tribunal al estimar que un Estado puede imponer a los partidos políticos "el deber de respetar y salvaguardar los derechos y libertades garantizados por la Convención, así como la obligación de proponer un programa político que no esté en contradicción con los principios fundamentales de la democracia". ${ }^{44}$

\section{Refah Partisi, apartado 99; Herri Batasuna, apartado 79.}

91 En concreto, en el asunto español el TEDH "conviene con los argumentos del Tribunal Supremo y del Tribunal Constitucional y considera que los actos y discursos imputables a los partidos políticos demandantes constituyen un conjunto que da una imagen neta del modelo de sociedad concebido y propugnado por tales partidos que está en abierta contradicción con el concepto de sociedad democrática. Por tanto, la sanción infligida a los demandantes por el Tribunal Supremo, confirmada luego por el Tribunal Constitucional, aun contando con el reducido margen de apreciación de que disponen los Estados, puede ser considerada razonablemente como obedeciendo a una necesidad social imperiosa" (apartado 91 de la sentencia).

92 Término textualmente utilizado por los jueces discrepantes en la sentencia Refah Partisi.

93 Sudre, François, Droit européen et international des droits de l'homme, París, Presses Universitaires de France, 2003, pp. 230 y ss.

94 Caso Refah Partisi (Partido de la Prosperidad), de 13 de febrero de 2003, apartado 103 . 
Este cambio en la orientación jurisprudencial puede venir motivado por la gran conmoción mundial que supuso el atentado del 11 de septiembre de 2001, que ha comportado un recrudecimiento en la lucha de los Estados contra el terrorismo, incluída la persecución de los partidos que apoyan dicha actividad y que puede tener una gran repercusión ante los nuevos retos a los que se enfrenta el continente europeo: la inmigración, el multiculturalismo, el asalto al poder de partidos con dudosos postulados democráticos..$^{95}$

Sin embargo, la mayoría de las sentencias posteriores al asunto Refah Partisi han puesto de manifiesto que en realidad no nos hallamos ante un giro en la trayectoria adoptada por el Tribunal en materia de partidos políticos. ${ }^{96}$ Esta decisión estaba motivada, únicamente, por la mayor amenaza que para el valor esencial de la democracia, protegida por el Convenio, implicaba la llegada al gobierno turco del fundamentalismo islámico, en el caso Refah Partisi, y se repitió en el caso Herri Batasuna cuando se demostró la vinculación de los partidos vascos demandantes con la organización terrorista vasca ETA.${ }^{97} \mathrm{La}$ valoración de la amenaza en juego elaborada por el TEDH ha dado pie a la crítica de varios autores, empezando por la opinión disidente emitida por tres jueces del caso

95 Desde el extremo opuesto, otro dato a tener en cuenta en la actualidad es la variación en la composición del TEDH con la incorporación de los países de Europa Central y Occidental (PECOS) que quizás ha supuesto una rebaja en los niveles de protección de los derechos fundamentales. Véase García San José, Daniel Ignacio, op. cit., nota 6, pp. 164 y ss.

96 Así, en el asunto Emek Partisi y Senol contra Turquía, de 31 de mayo de 2005, el Tribunal, a pesar de invocar la conocida doctrina del precedente del Partido de la Prosperidad (apartado 25 de la sentencia), rechaza que existiera la necesidad social imperiosa de adoptar la medida de disolver aquel partido político sobre la base de su programa (apartado 29 ) en el que, a juicio del Tribunal Constitucional turco, se buscaba dividir la integridad territorial de la nación turca, segregando a los kurdos (apartado 26). En consecuencia, el Tribunal Europeo declaró que se había violado el artículo 11 del Convenio. Muy similar a este asunto, invocando, igualmente, el precedente del Partido de la Prosperidad para condenar a Turquía, es el caso del Partido de la Democracia y el Cambio y otros contra Turquía, de 26 de abril de 2005.

97 En la sentencia, el TEDH recogió literalmente un acuerdo del Consejo de la Unión Europea sobre medidas para actuar contra el terrorismo, en cuyo anexo figura la lista de organizaciones terroristas que actúan en Europa, entre las que se encuentran ETA y, como parte integrante de la misma, "KAS, Xaki, Ekin, Jarrai-Haika-Segi, Gestoras proamnistía, Askatasuna, Batasuna (alias Herri Batasuna, alias Euskal Herritarrok"). 
Refah Partisi cuando se zanjó la cuestión, por primera vez, ante la tercera sección del Tribunal. ${ }^{98}$ Para los jueces minoritarios, una medida tan grave como es la disolución de un partido político sólo se puede aplicar a los casos más graves y dicha gravedad no concurría en el caso enjuiciado. ${ }^{99}$

En consonancia con los magistrados discrepantes, Lozano Contreras calificó dicho pronunciamiento de arriesgado al no estar fundamentado en razones de fondo sino de mera oportunidad política y dictado con finalidad preventiva y no represiva o sancionadora. ${ }^{100}$ Este primer tipo de objeciones cae por su propio peso, ya que esperar a que el Refah Partisi haya dado cumplimiento a sus pautas antidemocráticas para ponerle una cortapisa resultará ser, con toda probabilidad, una medida ya poco eficaz. Más fundada parece la crítica expresada por Tajadura cuando llama la atención sobre el hecho de que el TEDH "supedita la legitimidad de la disolución del partido a la 'entidad de la amenaza' que representa", 101 es decir que un partido "puede ser prohibido si es un partido de gobierno (aunque no haya llevado a cabo ni iniciado siquiera la puesta en marcha de su programa), y no puede serlo si es un partido minoritario". ${ }^{102}$ En otras palabras, el autor considera poco seguro jurídicamente el proceder del Tribunal porque no utiliza criterios jurídicos objetivables, sino criterios de mera oportunidad. Por ello, Tajadura propone que el Tribunal lleve a cabo su tarea de enjuiciamiento apoyándose solamente en el contenido del programa, en los objetivos del partido, independientemente de su peso político en las urnas. Aunque dicho autor no lo precisa, se puede

98 STEDH, de 31 de julio de 2001. Luego, el caso será elevado a la Gran Cámara, que alcanzará un parecer unánime, tal como ocurrió, más tarde, en el caso Herri Batasuna juzgado por la quinta sección del TEDH.

99 Véase el desarrollo de su argumentación en García Roca, Joaquín, "La problemática disolución del Partido de la Prosperidad ante el Tribunal Europeo de Derechos Humanos: Estado constitucional y control de las actuaciones de partidos fundamentalistas", Revista Española de Derecho Constitucional, núm. 65, 2002, pp. 309 y ss. El autor observa que en el juicio que se le hace a este partido, se considera que se pone en peligro la democracia por la actuación de algunos de sus dirigentes, lo que constituye un juicio de intenciones que ha de examinarse minuciosamente antes de decretar una sanción tan irreparable como es la disolución de un partido político. Ibidem, pp. 322 y ss.

100 Lozano Contreras, Fernando, "La jurisprudencia del Tribunal Europeo de Derechos Humanos en torno a la ilegalización de partidos políticos: el caso de Turquía", Revista Española de Derecho Internacional, vol. 54, núm. 2, 2002, p. 1009.

101 Tajadura Tejada, Javier, op. cit., nota 82, p. 312.

102 Idem. 
entender que el programa del partido habría de ser confrontado con las actuaciones y tomas de posiciones de los dirigentes para discernir si la letra y el espíritu forman una unidad o si, al contrario, la letra esconde un espíritu bien distinto del que ella expresa por sí sola. De hecho, el TEDH ha defendido la necesidad de esta confrontación de datos en los dos casos que nos ocupan. ${ }^{103}$ Defendiendo, sin embargo, la postura del Tribunal de Estrasburgo con respecto a este último razonamiento se han mostrado otros autores. Así, Barrero con una frase muy gráfica expone que si bien es cierto que la democracia no son sólo números, sino también valores, no lo es menos que "los números son decisivos a la hora de conseguir aquello que se quiere". 104

En la misma línea y con idéntica localización geográfica, en el caso Partido Socialista de Turquía (STP) y otros contra Turquía ${ }^{105}$ se analiza la disolución de este Partido por el Tribunal Constitucional conectando, una vez más, las libertades fundamentales contempladas en los artículos 10 y 11 del Convenio. El Tribunal Europeo estima que "no encuentra nada en el programa del STP que pueda pasar por una apelación a la violencia"106 $\mathrm{y}$, aunque no puede rechazarse, totalmente, que dicho programa se vea desmentido por las "actuaciones" o tomas de posición de sus dirigentes, tampoco queda probado dicho extremo. ${ }^{107}$ Es por ello que del presente caso no se puede colegir "la responsabilidad del STP por los problemas de terrorismo en Turquía"108 y que el Tribunal Europeo concluyó que "una medida tan radical" como la disolución del partido

103 Refah Partisi, apartado 101; Herri Batasuna, apartado 80.

104 Barrero Ortega, Abraham, "Reapertura del debate democracia abierta vs. democracia militante en la jurisprudencia del Tribunal Europeo de Derechos Humanos", en Montilla Martos, José Antonio (ed.), La prohibición de partidos políticos, Almería, Universidad de Almería, Servicio de Publicaciones, 2004, p. 199. Desde otro punto de vista, sin embargo, ha criticado la posición del TEDH en esta cuestión al evidenciar que la disolución de un partido político no sólo debe obedecer a una necesidad social imperiosa, sino que debe resultar proporcional al fin legítimo invocado por el poder público y es precisamente en la apreciación de este requisito cuando el Tribunal deja sin aclarar en qué se debe traducir su exigencia. Ibidem, p. 200.

105 STEDH de 12 de noviembre de 2003.

106 Apartado 45 de la sentencia.

107 Apartados 47-48 de la sentencia.

108 Apartado 49 de la sentencia. 
en cuestión resultaba desproporcionada e innecesaria en una sociedad democrática. ${ }^{109}$

Con independencia del "caso turco", existen otras sentencias, localizadas en diferentes enclaves geográficos, en las que el Tribunal de Estrasburgo ha tenido ocasión de pronunciarse sobre las, siempre vidriosas, relaciones entre el Poder Ejecutivo y los partidos políticos: destaca, por su importancia, el caso del Partido Comunista Rumano "NEPECERISTI" (PCN) y otros contra Rumania, ${ }^{110}$ en el que con motivo de la negativa de los tribunales rumanos de satisfacer la solicitud de registro del $\mathrm{PCN}$, apoyándose únicamente en su estatuto y su programa político, los demandantes alegaron ante la Corte Europea violación de su derecho a la libertad de asociación garantizado por el artículo 11 del Convenio. ${ }^{111}$ El Tribunal conecta, una vez más, los artículos 10 y 11 del CEDH y recuerda que no hay democracia sin ese ejercicio colectivo de la libertad de expresión que permite el pluralismo, reconociendo que un partido puede hacer campaña, por medios pacíficos a favor de un cambio de legislación y de las estructuras legales y constitucionales. ${ }^{112}$ De este modo, después de analizar los estatutos y el programa político del partido, concluye que no se aprecian en ellos signos que puedan evidenciar un llamamiento a la violencia ni a la dictadura del proletariado. ${ }^{113}$ Antes bien, observa que estos textos insisten en el respeto de la soberanía nacional, de la integridad territorial y del orden jurídico y constitucional del país, así como de los principios de la democracia, lo que constituye un elemento esencial. ${ }^{114}$ A la vista de todos estos vectores resuelve, finalmente, que una medida tan radical como la negativa a inscribir al PCN en el registro en tanto que partido político, incluso antes de haber comenzado sus actividades, parece desproporcionado con respecto al fin perseguido y, en consecuencia, no es necesario en una sociedad democrática. ${ }^{115}$

109 Apartado 50 de la sentencia.

110 STEDH, de 3 de febrero de 2005.

111 No fue éste el único motivo aducido, pues también fue invocado el artículo 14 (prohibición de discriminación), al sostener los litigantes que habían sido víctimas de una discriminación basada en sus opiniones políticas (apartado 3 de la sentencia).

112 Apartados 44 y 45 de la sentencia.

113 El TEDH tiene, así, en cuenta el contexto histórico, en concreto, la experiencia del comunismo totalitario en Rumania antes de 1989.

114 Apartado 54 de la sentencia.

115 Apartado 60 de la sentencia. 
Una situación parecida a la anterior, aunque más recientemente, ocurrió con el Partido Liberal fundado por el señor Linkov cuando se vio denegada la inscripción registral a causa de su proyecto político. En el caso Linkov contra República Checa, de 7 de diciembre de 2006, el Tribunal trata de conjugar el hecho de que la libertad de asociación no sea absoluta con el deber del Estado de usar con parsimonia su poder de restricción legítima de dicha libertad, para proteger instituciones estatales o derechos y libertades ajenos. Por ello, sostiene que "un partido puede hacer campaña a favor de un cambio de legislación o de las estructuras legales o constitucionales del Estado", con tal de que utilice medios legales y democráticos y que el cambio propuesto sea "compatible con los principios democráticos fundamentales". ${ }^{116}$ Precisando más, el órgano estrasburgués establece distintas pautas para determinar si la negativa a inscribir un partido político responde a una "necesidad social imperiosa". En concreto, hay que asegurarse de la existencia de indicios sobre el riesgo de un atentado suficiente y razonablemente próximo contra la democracia, de la imputabilidad al partido de los actos y discursos de los dirigentes que se han tomado en consideración, y de que los actos y discursos imputables al partido reflejen real y adecuadamente el ideario político del mismo. ${ }^{117}$ En definitiva, el Tribunal estima que "la negativa a inscribir un partido en el registro es una medida radical que sólo puede aplicarse en casos de la mayor gravedad". ${ }^{118}$ Por consiguiente, atendiendo al hecho de que el partido en cuestión no presenta un programa antidemocrático ni ha podido manifestar en actos y discursos un espíritu contrario a la democracia, concluye la vulneración del artículo 11 del CEDH. ${ }^{119}$

En el caso del Partido Presidencial de Mordovia contra Rusia, ${ }^{120} \mathrm{cu}-$ riosamente no se produce la negación de inscripción a priori, sino con posterioridad, ya que se deniega la renovación de inscripción de dicho partido político, lo que arrastra su disolución. ${ }^{121}$ A pesar de que la actuación del Ejecutivo no reviste tintes de tanta gravedad como en los casos examinados con anterioridad, pues estamos aquí ante una mera suspen-

\footnotetext{
116 Apartados 35 y 36.

117 Apartado 37.

118 Apartado 45.

119 Apartados 45 y 46.

120 STEDH, de 5 de octubre de 2004.

121 Apartado 11 de la sentencia.
} 
sión temporal, ya que el Presidium de la República de Mordovia revisó su decisión, tres años después, y ordenó la inscripción, ${ }^{122}$ el Tribunal Europeo pondera que el partido actor estuvo todo ese periodo sustancial de tiempo sin poder funcionar ni concurrir a las elecciones, por lo que decreta concederle una indemnización por los daños causados. ${ }^{123}$

En las últimas decisiones jurisprudenciales, el Tribunal de Estrasburgo continúa con su talante fuertemente garantista a favor de la subsistencia de los partidos políticos, en contra de las razones aducidas por los respectivos gobiernos dirigidas a su disolución o a su no inscripción.

En el caso Tsonev contra Bulgaria ${ }^{124}$ se analiza, nuevamente, la denegación de inscripción de un partido político por defectos de forma (en particular, al tener una denominación similar a la de otros partidos) y en cuanto al fondo, porque el gobierno búlgaro, apoyado en su Constitución y demás leyes aplicables de su ordenamiento jurídico interno, estimó que dicho partido contenía en su programa y otros escritos, objetivos contrarios a la unidad territorial y al orden público, además de que algunos de dichos objetivos eran coincidentes con los de otras formaciones políticas ya registradas. ${ }^{125}$ En lo que se refiere a las cuestiones de forma, el Tribunal no aprecia motivo de justificación en la conducta del Ejecutivo búlgaro, ya que dichos errores fueron subsanados, oportunamente; en cuanto a la denominación, los propios tribunales nacionales permitieron, con posterioridad, la inscripción de otro partido político con idéntico nombre. ${ }^{126}$ Por lo que respecta al ideario de este partido, a pesar de que se reconoce que los tribunales nacionales son los intérpretes, por excelencia, de su propia legislación, el Tribunal Europeo no está persuadido, sin embargo, de las conclusiones a las que aquéllos han llegado sobre las divergencias entre los escritos políticos del Partido Comunista de Bulgaria con la Constitución y el resto de la normativa búlgara, hasta el punto de que puedan constituir una base adecuada para justificar la injerencia de las autoridades en el derecho de constituir partidos políticos. ${ }^{127} \mathrm{Y}$ concluye:

122 Apartado 20 de la sentencia.

123 Apartados 29-31 de la sentencia.

124 STEDH, de 13 de abril de 2006.

125 Apartados 46 y 57 de la sentencia.

126 Apartado 56 de la sentencia.

127 Apartado 44 de la sentencia. 
generalmente, la experiencia política de los Estados miembros, ha mostrado que los partidos políticos con objetivos contrarios a los principios fundamentales de la democracia no han revelado tales objetivos en sus publicaciones oficiales hasta después de haber tomado el poder. El programa político de un partido puede esconder objetivos e intenciones diferentes de aquellos que proclama. Para comprobar que no existe engaño, el contenido del programa debe ser comparado con las acciones de los líderes del partido y las posturas que ellos defienden. ${ }^{128}$

La decisión del Tribunal de Estrasburgo se explica porque, a diferencia de los tribunales nacionales, no observa ningún contenido antidemocrático en el programa del Partido Comunista de Bulgaria, por lo que sólo la realización de sus acciones, posibilitadas por la inscripción, puede dar la medida exacta de sus verdaderos objetivos e intenciones políticas. ${ }^{129}$ En cualquier caso, el Tribunal se decanta por permitir la inscripción de la formación política, ya que cabría la posibilidad de su posterior disolución si llegara a materializar con acciones violentas sus ideales políticos. ${ }^{130}$

En el caso del Partido Democrático Cristiano del Pueblo contra Moldovia ${ }^{131}$ (PDCP), el supuesto encausado no es de denegación de inscripción, sino de disolución temporal: el 18 de enero de 2002, el ministro de Justicia de Moldovia impuso la suspensión de las actividades del PDCP como sanción a unas manifestaciones no autorizadas, a lo largo de toda la semana anterior. A petición del secretario general del Consejo de Europa, que invoca el artículo 52 del Convenio, y teniendo en cuenta la proximidad de las elecciones locales, el ministro de Justicia levantó la sanción impuesta en una decisión con fecha 8 de febrero de 2002. Llevado el asunto ante el Tribunal Europeo, éste precisó, de entrada, que la prohibición de las actividades del partido no estaba justificada y, por otro lado, que la naturaleza temporal de la decisión no tenía importancia decisiva a la hora de valorar la proporcionalidad de la medida adoptada ya que el corto espacio temporal de interrupción de las actividades afectaba, igualmente, al ejercicio de la libertad de expresión y a la consecución de los

128 Apartado 59. Cita en apoyo de su tesis la STEDH, Refah Partisi, de 13 de febrero de 2003, apartado 101.

129 Apartados 58 y 61 de la sentencia.

130 Apartado 60 de sentencia.

131 STEDH, de 14 de mayo de 2006. 
objetivos políticos. ${ }^{132}$ Por todo ello, concluyó, por seis votos contra uno, que había violación del artículo 11 del Convenio. Resulta llamativo comprobar, a través de esta sentencia, que el Tribunal de Estrasburgo somete a un mismo tratamiento, en cuanto a la apreciación de la posible violación del derecho de asociación, tanto una medida sumamente agresiva como es la disolución de un partido político, como la mera suspensión temporal de sus actividades.

En torno a la diversa problemática que presentan los partidos políticos, esta vez referida a la denegación de elegibilidad tanto al Parlamento letón como a los cargos municipales por parte de un antiguo miembro del Partido Comunista letón, el Tribunal Europeo estimó que se produjo una violación del artículo 11 del Convenio. En su apreciación el Tribunal subrayó que la inelegibilidad se fundó sobre un compromiso político del pasado y no sobre el comportamiento actual de la demandante, cuyas actividades públicas en el presente no revelaban falta alguna de respeto hacia los valores fundamentales del Convenio. Por consiguiente, la medida adoptada por el gobierno resulta desproporcionada a la pretensión de salvaguardar la seguridad nacional, no siendo necesaria en una sociedad democrática. ${ }^{133}$

\section{CONCLUSIONES}

El artículo 11 del Convenio Europeo de Derechos Humanos se ha visto perfilado por la jurisprudencia del Tribunal Europeo de Derechos Humanos que lo ha interpretado. Esta labor hermenéutica y de configuración del derecho de asociación sigue dominada por el enfoque que concede especial importancia al respeto y fomento de la democracia, pero precisando que no debe degenerar en una dictadura de las mayorías, sino permitir el reconocimiento apropiado de las minorías. Al pronunciarse sobre la definición del derecho de asociación, el Tribunal recoge las tradicionales dimensiones de la libertad positiva y negativa, poniendo el acento en su carácter de unión voluntaria de personas para lograr un determinado

132 Apartado 78 de la sentencia. Véase Tajadura Tejada, Javier, "La doctrina del Tribunal Europeo de Derechos Humanos sobre la prohibición de partidos políticos", Boletín Mexicano de Derecho Comparado, núm. 123, 2008, pp. 1431-1475.

133 STEDH, de 17 de junio de 2004, Danoka contra República de Letonia, apartados 106-111. 
fin ajustado a derecho, mediante el establecimiento de un ente dotado de estabilidad. El Tribunal de Estrasburgo especifica, además, que el ejercicio del derecho de asociación corresponde tanto a los individuos como a la propia asociación.

Las afirmaciones más reiteradas y comunes a las formaciones sobre las que han versado la mayor parte de las sentencias del Tribunal (partidos políticos y sindicatos), se contraen a dos. La primera viene referida a los posibles límites al ejercicio del derecho de asociación, cuyo establecimiento legítimo requiere una adecuada valoración mediante el principio de proporcionalidad. En el caso de los partidos políticos, el Tribunal adopta una postura fuertemente garantista en favor de su subsistencia, lo que le lleva a dar preferencia al reconocimiento de las restricciones estatales establecidas a posteriori, salvo determinados casos de excepción en los que la intervención preventiva se erija en indispensable para salvaguardar la democracia. La segunda idea nuclear avanzada por el Tribunal Europeo estriba en la contundente afirmación de la interrelación medular de los derechos fundamentales, llegando a subrayar, en una especie de admisión del efecto dominó, que la violación de unos implica la conculcación de otros. Centrándonos en la libertad de asociación, la define como un ejercicio colectivo de la libertad de expresión, que permite el pluralismo sin el que no hay democracia. Ahora bien, esta tolerancia y espíritu de apertura que deben caracterizar el Estado democrático no constituyen principios ilimitados, sino que resulta intolerable todo lo que amenaza la paz, o la supervivencia de una sociedad, como sería la hipótesis de los actos terroristas. ${ }^{134}$ Además, desde el extremo opuesto el Tribunal considera que la libertad de opinión, de conciencia y de religión integra y potencia los objetivos de la garantía de la libertad de asociación. Del mismo modo, conecta el derecho de asociación con la libertad de reunión y, en algunas circunstancias, con el respeto a la vida privada y familiar. En consecuencia, una vulneración de estos derechos constituye ipso facto una injerencia injustificada en el ejercicio del derecho de asociación.

Quedan abiertas dos líneas jurisprudenciales pendientes de posteriores desarrollos: la inclusión del derecho a la negociación colectiva como elemento esencial de la libertad sindical y la ilegalización de los partidos

134 Navarro Massip, Jorge, "El delito de ultrajes a España y la libertad de expresión”, Revista Aranzadi Doctrinal, núm. 7, 2009. 
políticos. La diferencia básica entre las dos interrogantes radica en que, con respecto a la primera, resulta muy probable que, en aras de la seguridad jurídica, el Tribunal mantenga la línea abierta a favor de la consideración de la negociación colectiva como parte integrante del contenido esencial de la libertad sindical. Mientras que la segunda cuestión, al tratarse de soluciones adoptadas ante situaciones puntuales de evidente riesgo contra la democracia, es probable que no se adopten más que cuando se repitan dichas situaciones de peligro. ${ }^{135}$

Otro tema destacable es la interrelación de la dimensión individual y de la social que resulta ser especialmente aguda en el caso en que los titulares del derecho de asociación sean funcionarios del Estado, al ser sujetos que tienen una especial responsabilidad frente a la sociedad. De hecho, suele ser una pauta común para la admisión del ejercicio del derecho de huelga por parte de dichos funcionarios que se exija el mantenimiento de los servicios esenciales de la comunidad. Este postulado se basa en que la misión principal de los funcionarios es el servicio a los ciudadanos y a los intereses generales. Dicho postulado se debe, no obstante, conjugar con el respeto del contenido esencial de su derecho de libertad sindical que puede verse condicionado y matizado, pero nunca restringido totalmente. En concreto, la supresión total del ejercicio del derecho de huelga para estos sujetos impediría la posibilidad de legítima defensa de sus intereses profesionales, por lo que se debe admitir, siempre y cuando queden suficientemente garantizados los servicios esenciales de los que deben disfrutar los particulares.

135 De hecho, el TEDH no se ha llegado a plantear la interesante cuestión de si el mecanismo tan radical de disolver un partido político puede evitarse, en algunos casos, determinando simplemente que sus dirigentes pierdan la condición de parlamentarios.

Fecha de recepción: 23 de marzo de 2010.

Fecha de dictamen: 18 de mayo de 2010. 